\title{
Blastic plasmacytoid dendritic cell neoplasm: First retrospective study in the Czech Republic
}

\author{
M. CERNAN ${ }^{1}$, T. SZOTKOWSKI ${ }^{1, *}$, M. HISEMOVA ${ }^{2}$, P. CETKOVSKY ${ }^{2}$, L. SRAMKOVA ${ }^{3}$, J. STARY ${ }^{3}$, Z. RACIL ${ }^{4}$, J. MAYER ${ }^{4}$, J. SRAMEK ${ }^{5}$, P. JINDRA ${ }^{5}$, \\ B. VISEK ${ }^{6}$, P. ZAK ${ }^{6}$, J. NOVAK ${ }^{7}$, T. KOZAK ${ }^{7}$, T. FURST ${ }^{8}$, T. PAPAJIK ${ }^{1}$
}

\begin{abstract}
${ }^{1}$ Department of Hemato-Oncology, Faculty of Medicine and Dentistry, Palacky University Olomouc and University Hospital Olomouc, Olomouc, Czech Republic; ${ }^{2}$ Institute of Hematology and Blood Transfusion, Prague, Czech Republic; ${ }^{3}$ Department of Pediatric Hematology and Oncology, 2nd Faculty of Medicine, Charles University and Motol University Hospital, Prague, Czech Republic; ${ }^{4}$ Department of Internal Medicine, Hematology and Oncology, Masaryk University and University Hospital Brno, Brno, Czech Republic; ${ }^{5}$ Department of Hemato-Oncology, University Hospital Pilsen, Pilsen, Czech Republic; ${ }^{6} 4$ th Department of Internal Medicine - Hematology, University Hospital Hradec Kralove, Hradec Kralove, Czech Republic; ${ }^{7}$ Department of Internal Medicine and Hematology, University Hospital Kralovske Vinohrady and Third Faculty of Medicine, Charles University, Prague, Czech Republic; ${ }^{8}$ Department of Mathematical Analysis and Application of Mathematics, Faculty of Science, Palacky University Olomouc, Olomouc, Czech Republic
\end{abstract}

${ }^{*}$ Correspondence: tomas.szotkowski@fnol.cz

Received May 7, 2019 / Accepted September 11, 2019

\begin{abstract}
Blastic plasmacytoid dendritic cell neoplasm (BPDCN) is a rare hematologic malignancy with aggressive behavior and poor prognosis. We present the first retrospective analysis mapping its incidence and therapeutic outcomes in patients diagnosed and treated from 2000 to 2017 in the Czech Republic. The cohort comprised 14 patients (10 males, 4 females) with a median age at diagnosis of 39 years (range, 5-68 years). Initially, skin involvement was noted in 10 (71\%) patients and bone marrow infiltration was present in 9 (64\%). The first complete remission was achieved in 6/14 (43\%) patients after acute lymphoblastic leukemia/lymphoma induction therapy and in 3/14 (21\%) patients after acute myeloid leukemia regimen. Nine patients underwent allogeneic hematopoietic cell transplantation, with two patients achieving the first complete remission only after allogeneic transplantation. Patients undergoing allogeneic hematopoietic cell transplantation had longer overall survival than those treated without transplantation (the median survival over the period 16.4 vs. 8.1 months). Relapse of the disease was a significant predictor of mortality ( $\mathrm{p}=0.05)$. Over the study period, patients' survival ranged from 3.3 to 44.2 months, with a median overall survival of 13 months. Our results revealed an effectivity of allogeneic hematopoietic cell transplantation on complete remission achievement in refractory/relapsed disease. The study aimed to present the actual data from the Czech Republic and thus contribute to a global understanding of BPDCN.
\end{abstract}

Key words: blastic plasmacytoid dendritic cell neoplasm, BPDCN, allogeneic hematopoietic cell transplantation, SL-401

Blastic plasmacytoid dendritic cell neoplasm (BPDCN) is a rare hematologic malignancy with frequent primary skin involvement and coexpression of CD4 and CD56 [1]. The real incidence of the disease is unknown and is estimated at $0.4 \%$ of all hematologic malignancies [2]. The median age at diagnosis is $60-70$ years and the disease is up to three times more frequent in males [3]. Despite frequent initial indolent manifestation with skin involvement, the disease has a tendency to rapid systemic dissemination with infiltration of bone marrow and extramedullary organs. At diagnosis, skin involvement is manifested in most patients; however, in as many as $80 \%$ of patients, other organs are involved, namely bone marrow, lymph nodes, spleen, liver and CNS, especially during progression or relapse of the disease $[4,5]$.
The diagnosis of BPDCN has undergone many changes over the years but still remains problematic as other hematologic malignancies may share some morphological and immunophenotypic features with BPDCN. The current diagnostic criteria are based on the 2016 WHO Classification of Tumors of Hematopoietic and Lymphoid Tissues [6]. The diagnosis is characterized by coexpression of CD4 and CD56 with variable expression of other markers specific for dendritic cells, namely CD123, CD43, BDCA-2/CD303 and TCL1, with lack of expression of lineage-specific antigens for $\mathrm{B}$ and $\mathrm{T}$ cells, myeloid, monocytes and NK cells [7].

At present, there is no specific cytogenetic or molecular change pathognomonic for BPDCN. Frequent cytogenetic findings are complex karyotype changes with recurrent 
aberrations on chromosomes 5q, 12p, 13q, 6q, 15q and 9 $[8,9]$. Patients with BPDCN may have a broad spectrum of molecular genetic changes including CDKN2A deletion and mutations of TET2, TP53 or FLT3, potentially used both for prognostic stratification and as therapeutic targets for novel drugs in the future [10-12].

Our knowledge of the treatment is based on retrospective analyses of cohorts published in the literature. Both guidelines and large prospective studies are still lacking. Analyses of treatment outcomes have shown higher complete remission (CR) rates and longer overall survival (OS) with induction chemotherapy for acute lymphoblastic leukemia (ALL-like therapy) followed by allogeneic hematopoietic cell transplantation (HCT), compared to other induction or consolidation chemotherapy regimens [13-15]. Despite initially high rates of CR induced by intensive chemotherapy, the disease frequently relapse and the median OS does not exceed two years [16, 17]. Allogeneic transplantation in the first CR in adults is of crucial importance for prolonging OS [18]. The first prospective clinical study of BPDCN patients showed the effectiveness of SL-401, a recombinant protein composed of diphtheria toxin fused to IL-3, with a response rate of $64 \%$ patients [19]. Other drugs like venetoclax and bortezomib are being tested as a potential treatment for BPDCN $[20,21]$.

The aims of the present study were to describe the disease etiology, clinical presentation and treatment outcomes in patients in the Czech Republic and to compare the obtained data with those in the literature.

\section{Patients and methods}

Patients. The study is a retrospective analysis of BPDCN cases diagnosed and treated in Czech hematology centers between January $1^{\text {st }}, 2000$ and December 31 $1^{\text {st }}$, 2017. All university and regional hematology centers providing care to adult (18 centers) and pediatric ( 8 centers) patients in the Czech Republic were invited to study. The participating centers were asked to search their registries and databases to identify patients diagnosed with BPDCN. The Czech literature was searched to find previously published case reports from the Czech Republic as well. Another search was performed in DATOOL, a Czech Leukemia Study Group for Life database containing data on acute leukemia cases in the Czech Republic, to find patients with acute leukemia and the BPDCN immunophenotype.

Inclusion criteria. The diagnosis of BPDCN was made by pathologists from the participating centers. A careful review of the reported cases was done. Inclusion criteria required coexpression of CD4 and CD56 with variable expression of other dendritic cell-specific markers (CD123, CD43, BDCA-2/CD303, TCL1 and LCA/CD45) in combination with the negativity of lineage-specific antigens. Cases with isolated coexpression of CD4 and CD56 with no other dendritic markers were included if negativity for strong $\mathrm{B}$ (CD19 or CD10/CD20/CD22/CD79a) and T (CD3) lineage, myeloid and monocytic (myeloperoxidase, nonspecific esterase, CD11c, CD14, CD64 or lysozyme) markers were proved. Because of retrospective study design and long study period, not all currently known markers were examined in all patients at the time of diagnosis. All the reported cases met the current criteria for diagnosing BPDCN according to 2016 WHO Classification of Tumors of Hematopoietic and Lymphoid Tissues $[6,22]$. The study comprised 14 cases reported by the hematology centers, of whom three had been published as case reports in Czech literature. In 2003, 2007, 2013, 2015 and 2017, one case each was reported; there were two cases in 2009 and three in 2014. As many as four BPDCN cases were noted in 2016. For all identified cases, their anonymized demographic data, medical history, clinical picture and baseline laboratory parameters, histological and immunophenotypic profiles of the malignancy at diagnosis, therapy administered and treatment outcomes were retrieved. All patient data were obtained and analyzed in accordance with the Declaration of Helsinki, Czech legislation and conditions set by the participating centers, including informed consent.

Initial staging. The degree of clinical manifestation of BPDCN was assessed as skin involvement and extracutaneous involvement of the spleen, liver, lymph nodes, bone marrow ( \pm peripheral blood), CNS and other organs. Cases with the involvement of two or more organ systems were considered as a generalized disease. The diagnosis of acute leukemia with the BPDCN immunophenotype was made if the blast count in bone marrow was at least $20 \%$. For infiltration of the CNS and peripheral blood, the number of circulating blasts was not of key importance. Comorbidities were defined as diseases and conditions listed in the Hematopoietic Cell Transplantation - Comorbidity Index [23]. Diseases and conditions not listed there were considered insignificant.

Therapy and treatment response assessment. Based on primary indication, the administered therapy was classified into ALL/lymphoma-like (regimens for treating acute lymphoblasticleukemia and lymphoma), AML-like (regimens for treating acute myeloid leukemia) and $\mathrm{HD}$-AraC-like in the HAM regimen (high-dose cytarabine and mitoxantrone) used to treat lymphoid and myeloid malignancies. Supportive care during therapy was provided in accordance with the standards of the participating centers. Therapeutic response was defined as CR with the disappearance of all signs of the disease detectable by clinical, laboratory and imaging examinations. In the case of initial bone marrow involvement, the therapeutic response was evaluated using the 2017 European LeukemiaNet recommendations for AML [24]. In patients with skin or other organ involvement, the response was classified as CR, partial remission (PR), stable disease (SD) or progressive disease (PD) according to modified criteria for non-Hodgkin lymphomas established by Cheson et al. [25]. Relapse was defined as any new signs of the disease detected by clinical, laboratory or imaging examinations in a patient who had already achieved complete remission. In the study, OS was defined as the time from diagnosis to the 
last contact with the patient or until December $31^{\text {st }}, 2017$ (end of the study observation period) in patients with the last documented contact in 2018. The duration of the first CR was defined as the time from the achievement of the first CR to relapse or the end of the observation period for patients in the first CR.

Statistical methods. Despite the apparent limitations due to the small sample size, statistical analysis to compare discrete variables was carried out using Fischer's exact test in a four-fold contingency table. The level of statistical significance in the tests was set at $p=0.05$. With a small sample size, statistical analysis is limited by the fact that some existing phenomena may not be expressed sufficiently.

\section{Results}

The analyzed cohort consisted of 14 patients with a median age at diagnosis of 39 years (range, 5-68 years). There were three pediatric patients aged 5, 8 and 16 years. The cohort comprised 10 males with a median age of 47 years (range, 5-68 years) and four females with a median age of 27 years (range, 8-68 years). Prior to BPDCN diagnosis, none of the patients were treated for other malignancies. When being diagnosed with BPDCN, one patient was suspected of having synchronous gynecological cancer. However, given her advanced hematological malignancy with an adverse course, the patient's suspicious gynecological neoplasm was not histologically confirmed.

Clinical picture. The extent of involvement at BPDCN diagnosis varied considerably across the patients. Characteristic skin involvement was initially present in 10/14 (71\%) patients. Purely cutaneous manifestations of the malignancy at diagnosis was observed in only four $(29 \%)$ patients. The character and extent of skin lesions were rather hetero- geneous (papules, nodules, ulcerations), with six patients initially having localized skin involvement (of whom three had leg skin lesions) and generalized skin lesions being reported in four patients. Bone marrow infiltration by blast cells was noted in 9/14 (64\%) patients. In one case, the disease was initially manifested as acute leukemia with the BPDCN immunophenotype and no other extramedullary involvement. Blasts were present in the peripheral blood of eight out of the nine patients with bone marrow infiltration. In 6/14 (43\%) of patients, the liver and/or spleen or lymph nodes were initially enlarged. None of the patients had isolated liver or lymph node enlargement at diagnosis. In only one patient, cerebrospinal fluid infiltration by blast cells was initially detected (cerebrospinal fluid of three patients was not initially examined). Nine (63\%) patients were initially diagnosed with the generalized disease. Involvement of the jejunum, nasopharynx or lungs was reported in one patient each. Table 1 shows the extent of involvement at diagnosis and the first relapse in the patient cohort.

Morphology and immunophenotype profile. The morphological features of blast cells in histological samples were rather heterogeneous. Morphologically, BPDCN cells were described as medium-sized to large, with delicate cytoplasm, often resembling poorly differentiated myeloblasts or lymphoblasts. Therefore, a definitive diagnosis required immunohistochemistry. With bone marrow involvement, normal hematopoiesis was suppressed or residual. Skin lesion samples often exhibited massive blast cells infiltration into the dermis with perivascular spread and no infiltration into the epidermis.

In all patients, the diagnosis was made based on characteristic immunohistochemistry or flow cytometry profiles in the samples. The diagnostic samples in the patient cohort are listed in Table 1. For BPDCN diagnosis in all patients,

Table 1. Extent of involvement at diagnosis, first relapse and diagnostic sample.

\begin{tabular}{|c|c|c|c|c|c|c|c|c|}
\hline \multirow[b]{2}{*}{$\mathbf{P t}$} & \multirow[b]{2}{*}{ Age/gender } & \multicolumn{5}{|c|}{ Extent of involvement at diagnosis } & \multirow[b]{2}{*}{ Diagnostic sample } & \multirow[b]{2}{*}{ Site of the first relapse } \\
\hline & & Skin & $\begin{array}{c}\text { Lymph } \\
\text { Nodes }\end{array}$ & $\begin{array}{l}\text { Liver/ } \\
\text { spleen }\end{array}$ & $\begin{array}{c}\text { Bone } \\
\text { marrow }\end{array}$ & Other & & \\
\hline 1 & $18 \mathrm{~F}$ & - & - & - & + & - & $\mathrm{BM}$ & $\mathrm{BM}$, gingivae \\
\hline 2 & $35 \mathrm{~F}$ & - & - & + & + & - & $\mathrm{BM}$ & - \\
\hline 3 & $5 \mathrm{M}$ & + & + & + & + & CSF & $\mathrm{BM}$ & CSF \\
\hline 4 & $8 \mathrm{~F}$ & + & - & - & - & - & skin & - \\
\hline 5 & $16 \mathrm{M}$ & - & + & + & - & lungs & $\mathrm{LN}$ & BM \\
\hline 6 & $68 \mathrm{~F}$ & + & - & + & + & - & skin & - \\
\hline 7 & $51 \mathrm{M}$ & + & + & - & + & jejunum & $\mathrm{BM}$ & NS \\
\hline 8 & $34 \mathrm{M}$ & + & - & - & + & - & BM, skin & - \\
\hline 9 & $52 \mathrm{M}$ & - & + & - & + & nasopharynx & BM, nasopharynx & - \\
\hline 10 & $43 \mathrm{M}$ & + & + & + & + & - & BM, skin & NS \\
\hline 11 & $56 \mathrm{M}$ & + & + & + & + & - & $\mathrm{BM}$ & skin, BM \\
\hline 12 & $68 \mathrm{M}$ & + & - & - & - & - & skin & - \\
\hline 13 & $22 \mathrm{M}$ & + & - & - & - & - & skin & - \\
\hline 14 & $64 \mathrm{M}$ & + & - & - & - & - & skin & skin \\
\hline
\end{tabular}

F - female, M - male, CSF - cerebrospinal fluid, BM - bone marrow, LN - lymph node, NS - not stated 
coexpression of CD4 and CD56 and the absence of lineagespecific markers were crucial. Expressions of other markers supporting the diagnosis of BPDCN in accordance with 2016 WHO recommendations were only selectively studied. In the tumor cells of all patients tested for CD123 and CD43, expression was confirmed. Leukocyte common antigen (LCA) was detected in 6/7 (87\%) patients with available tests. CD303 (BDCA2) and TCL1 expressions were not investigated in any patients. Table 2 shows the immunohistochemistry profiles of BPDCN in individual patients.

Laboratory findings. Blood count results at diagnosis were available for 13 patients. In those with bone marrow infiltration (9/14 patients), anemia (median hemoglobin 114 ; 45-127 g/l) and thrombocytopenia (median 67; $\left.24-251 \times 10^{9} / 1\right)$ with variable leukocytosis $\left(\geq 10 \times 10^{9} / 1\right)$ dominated the peripheral blood. Leukocytosis (median 23.2; $\left.18.0-68.6 \times 10^{9} / 1\right)$ was present in $5 / 9(56 \%)$ patients with bone marrow involvement. Blasts in the peripheral blood were present in 8 patients; in one case, bone marrow infiltration was only detected in a trephine biopsy specimen with no presence of blasts in the peripheral blood. In patients without bone marrow infiltration, blood count values were normal for age and gender; the only exception was a child with adenomegaly, hepatosplenomegaly and lung involvement who was initially reported to have pancytopenia. The median CRP at diagnosis was $16(1-190) \mathrm{mg} / \mathrm{l}$ (normal value was defined $<5 \mathrm{mg} / \mathrm{l}$ ). Infectious complications (invasive aspergillosis) were initially diagnosed in one patient with a history of prolonged neutropenia (CRP at diagnosis $29 \mathrm{mg} / \mathrm{l}$ ). Table 3 shows selected laboratory findings at diagnosis.

Genetic profile. Karyotyping was performed at diagnosis in $11 / 14$ (79\%) patients. Normal karyotype was found in 5/14 (36\%) patients. Structural or numerical changes in chromosome 8 were reported in $4 / 14$ (29\%) patients. Trisomy 8 , mosaicism - trisomy and tetrasomy 8 , and translocation $(6 ; 8)(\mathrm{p} 21.1 ; \mathrm{q} 24)$ idic $(7)$ were detected in one patient each. Translocation $(6 ; 8)$ was identified in another patient as part of complex chromosomal changes. Complex karyotype ( $3 \geq$ aberrations in a single clone) was reported in two patients. Molecular biology examination using PCR was conducted in 10 patients. The range of examinations performed in individual patients was rather varied, mainly including molecular markers typical for myeloid malignancies. Mutation in the FLT3 gene was not present in 5/6 patients with available examinations. One patient had FLT3-Asp835 and NPM1 mutations, together with trisomy 8. Mutation in the NPM1 gene was absent in another three patients with available tests. In $3 / 14(21 \%)$ patients, a mutation in the WT1 gene was found. Table 3 clearly shows cytogenetic and molecular biology findings in individual patients.

Therapy and follow-up. All patients were treated with curative intention; initially, no patient received symptomatic therapy only. In 13 patients with available time data, the median time from diagnosis to treatment initiation was 4 days (range, 2-112 days). The upper range of the limit, 112 days, pertains to a patient who initially refused treatment. In a patient with pulmonary aspergillosis present initially, the time to therapy initiation was 43 days.

The first-line therapy (induction) according to protocols for acute lymphoblastic leukemia/lymphoma (ALL/ lymphoma-like) was used in 10 patients. Of those, six achieved CR, two patients had stable disease and another two patients progressed on therapy (PD). Both patients initially treated according to protocols for AML achieved CR. One patient treated with a high-dose cytarabine protocol (HD-AraC-like) achieved CR with incomplete hematopoietic recovery (iCR) and another one had SD. As many as 9/14 (64\%) patients achieved CR after first-line therapy (of

Table 2. Immunohistochemistry profiles of BPDCN at diagnosis.

\begin{tabular}{|c|c|c|c|c|c|c|c|c|c|c|c|}
\hline \multirow{2}{*}{ Pt. } & \multicolumn{7}{|c|}{ Common BPDCN markers } & \multicolumn{4}{|c|}{ Myeloid, B and T-lymphoid lineage specific markers } \\
\hline & $\mathrm{CD} 4$ & CD56 & CD43 & CD123 & CD45 & CD303 & TCL1 & MPO & CD19 & CD22 & CD3 \\
\hline 1 & + & + & $\mathrm{ND}$ & ND & ND & ND & ND & - & - & - & - \\
\hline 2 & + & + & ND & + & ND & ND & ND & - & - & - & - \\
\hline 3 & + & + & ND & ND & ND & ND & ND & - & - & - & - \\
\hline 4 & + & + & + & ND & + & ND & ND & - & - & ND & - \\
\hline 5 & + & + & + & ND & + & ND & ND & - & - & ND & - \\
\hline 6 & + & + & ND & ND & + & ND & ND & - & ND & ND & - \\
\hline 7 & + & + & ND & + & ND & ND & ND & - & - & ND & ND \\
\hline 8 & + & + & + & + & ND & ND & ND & - & - & - & - \\
\hline 9 & + & + & + & + & ND & ND & ND & - & - & - & - \\
\hline 10 & + & + & $\mathrm{ND}$ & + & ND & ND & ND & - & - & - & - \\
\hline 11 & + & + & $\mathrm{ND}$ & + & + & ND & ND & - & - & - & - \\
\hline 12 & + & + & + & ND & + & ND & ND & - & - & $\mathrm{ND}$ & - \\
\hline 13 & + & + & + & ND & + & ND & $\mathrm{ND}$ & ND & ND & - & - \\
\hline 14 & + & + & ND & + & - & ND & ND & - & - & - & - \\
\hline
\end{tabular}

Pt. - patient, ND - not done, MPO - myeloperoxidase, TCL1 - T-cell leukemia/lymphoma protein, + present marker $(\geq 10 \%),-$ bsent marker $(<10 \%)$ 
Table 3. Laboratory findings, cytogenetics and molecular biology at BPDCN diagnosis.

\begin{tabular}{|c|c|c|c|c|c|c|c|}
\hline \multirow{2}{*}{ Patient } & WBCs & Hemoglobin & Platelets & Blasts (PB/BM) & CRP & \multirow{2}{*}{ Cytogenetics } & \multirow{2}{*}{ Molecular biology } \\
\hline & $\times 10^{9} / 1$ & $\mathrm{~g} / 1$ & $\times 10^{9} / 1$ & $\%$ & $\mathrm{mg} / \mathrm{l}$ & & \\
\hline 1 & 3.8 & 88 & 37 & $30 / 63$ & 5 & ND & ND \\
\hline 2 & 23.2 & 114 & 89 & $61 / 90$ & 3 & $46, \mathrm{XX}$ & FLT3-, NPM1-, DNMT3A- \\
\hline 3 & 68.6 & 119 & 67 & $65 / 85$ & 8 & $\mathrm{CK}$ & $\begin{array}{l}\text { RUNX1/RUNX1T1-, CBFB- } \\
\text { MYH11, PML/Rara-, FLT3/ITD- }\end{array}$ \\
\hline 4 & 4.8 & 125 & 290 & $0 / 0$ & 6 & $46, \mathrm{XX}$ & MLL-, ETV6- \\
\hline 5 & 3.0 & 77 & 66 & $0 / 0$ & 55 & $46, X Y$ & $M L L-$, FLT3/ITD- \\
\hline 6 & 0.7 & 73 & 86 & $0 / 66$ & 29 & $\begin{array}{l}47, \mathrm{XX}(+8) / \\
48, \mathrm{XX}(+8)\end{array}$ & ND \\
\hline 7 & 41.5 & 45 & 64 & $38 / 60$ & 16 & $48, \mathrm{XX}(+8)$ & $\begin{array}{l}\text { NPM1+, } \\
\text { FLT3-Asp835+ }\end{array}$ \\
\hline & & & & & & & $\begin{array}{l}\text { WT1 +, } \\
\text { PML/Rara- }\end{array}$ \\
\hline 8 & 1.7 & 116 & 103 & $4 / 86$ & 28 & $45, X Y(-9)$ & $\begin{array}{l}\text { AML1-ETO, } \\
\text { CBFB-MYH11-, } \\
\text { FLT3/ITD- }\end{array}$ \\
\hline 9 & 3.5 & 88 & 47 & $16 / 88$ & 29 & $\begin{array}{c}\text { ND } \\
46, X Y\end{array}$ & WT1+ \\
\hline 10 & 18.0 & 123 & 24 & $75 / 64$ & 190 & 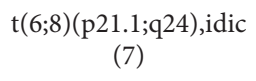 & WT1+, NPM1- \\
\hline 11 & 23.0 & 127 & 251 & $43 / 52$ & 60 & $46, X Y$ & $\begin{array}{l}\text { TP53-, WT1-, CEBPA-, FLT3, } \\
\text { NPM1- }\end{array}$ \\
\hline 12 & 8.5 & 172 & 243 & $0 / 0$ & 3 & $46, X Y$ & JAK2 (V617F)- \\
\hline 13 & 5.1 & 164 & 332 & $0 / 0$ & 1 & CK & ND \\
\hline 14 & ND & ND & $\mathrm{ND}$ & $0 / 0$ & ND & ND & $\mathrm{ND}$ \\
\hline Median & 5.1 & 116 & 86 & $41^{*} / 66^{*}$ & 16 & --- & --- \\
\hline
\end{tabular}

WBCs - white blood cells, PB - peripheral blood, BM - bone marrow, CRP - C-reactive protein, ND -not available/done, CK - complex karyotype ( $\geq 3$ aberrations), * only calculated for patients with blasts detected

those, one achieved iCR only). Stable disease was achieved in 3 patients and 2 others had PD. As prophylaxis of CNS involvement, a combination of cytarabine, methotrexate, and dexamethasone were intrathecally administered to seven patients and methotrexate alone to two patients, in accordance with relevant protocols in the first-line therapy.

The second-line therapy (reinduction) was administrated to patients not achieving CR after induction. Among six patients who failed to achieve CR after the first-line therapy (including one with $\mathrm{iCR}$ ), five received reinduction; the remaining patient with $\mathrm{PD}$ received symptomatic, palliative care only. In the second-line therapy setting, one patient received ALL/lymphoma-like reinduction with a duration of SD, two patients underwent AML-like reinduction with one $\mathrm{CR}$ and one SD. Patient with iCR after first-line therapy achieved CR after allogeneic HCT in the second-line therapy. Radiotherapy was used in one patient with the achievement of PR. After second-line therapy, 10 (71\%) patients were in $\mathrm{CR}$, two had SD, one patient was in $\mathrm{PR}$ and another one had PD. Three patients never achieved $\mathrm{CR}$ in the course of their therapy.

A total of nine patients underwent allogeneic HCT including one patient who was transplanted twice. Of the
10 allogeneic HCTs, six were performed after myeloablative conditioning and four after reduced-intensity conditioning. No patient underwent autologous HCT. Of the 10 allogeneic HCTs, three were from the related donors (one being haploidentical) and seven from unrelated donors, with the matches being 10/10 and 9/10 in three cases each and only 8/10 HLA alleles in one case. Before the first allogeneic HCT, five patients were in CR (including one with iCR), two were in the first relapse and two had SD. Following the first allogeneic HCT, nine patients were in CR. The second HCT was performed in a 5-year-old patient for the second isolated relapse of the disease in the bone marrow after the first allogeneic HCT. Prior to the second HCT, the third remission was achieved with clofarabine.

The relapse of the disease after the initial treatment response was noted in seven patients. Of those, two experienced two relapses and one patient even three relapses. At first relapse, skin involvement was present in two patients, in one case in combination with bone marrow infiltration. Bone marrow with gingival infiltration and bone marrow alone and CNS involvement were seen in one patient each. In two patients, no relapse site was stated. The second relapse was noted in 3 patients (in two cases bone marrow and one 
patient with skin involvement). The third relapse was seen in a 5-year-old patient with systemic disease dissemination (bone marrow, skin, CNS). Table 1 provides information of involvement at the first relapse in the patient cohort. The first relapse was treated with AML-like therapy in two patients (one achieved CR) and allogeneic HCT in another two (both achieved second CR). Another patient achieved the second CR after ALL/lymphoma-like therapy. Two patients died of disease progression. In the second relapse one patient received only palliative care. The 5 -year-old patient achieved third CR after clofarabine, but underwent third relapse soon with just palliative care. Radiotherapy to treat BPDCN was used in only three patients (for skin involvement in two patients and for the CNS in one patient with relapse). Table 4 provides an overview of treatment in the patient cohort.

Over the study period, patients' survival ranged from 3.3 to 44.2 months, with a median OS of 13 months. Initially, generalized disease and bone marrow involvement were not associated with higher mortality $(\mathrm{p}=0.20)$. Patients undergoing HCT had longer OS than those who were not transplanted (the median survival over the period 16.4 vs 8.1 months). However, allogeneic HCT did not have a significant effect on mortality reduction over the study period $(\mathrm{p}=0.62)$. The first remission lasted for a median of 12.2 months (range, 1.0-42.7 months). Disease relapse was a significant predictor of mortality $(p=0.05)$. As of the day of the assessment, five patients were alive, of whom four were in CR and one had
PR. A total of seven patients died of disease progression and two patients died of post-transplant complications (both were in CR). Figure 1 provides an overview of the patient cohort.

\section{Discussion}

This is the first study on BPDCN in the Czech Republic. The limitations are the retrospective study design and generally rare incidence of the disease with only several cases being reported each year. Of the 14 patients, ten were diagnosed in the last five years (2013-2017) of the study, suggesting that the disease was underdiagnosed in the previous time period (2000-2012). The reasons may be repeated changes of its name and diagnostic criteria as well as lower availability of immunohistochemistry and flow cytometry tests or data in registries and databases of individual centers. In the present study, the median age at diagnosis was 51 years (excluding pediatric patients). Similarly, in a US study, the median age at diagnosis (in patients over 20 years of age) was 52 years (range, 20-93 years) [17].

Most frequently, the first symptoms that make patients seek medical help are skin lesions or manifestations stemming from the lack of blood cells due to the bone marrow infiltration. The extent and character of skin lesions may vary greatly; both solitary and disseminated red to purplish nodules, papules or bruises have been reported [3,

Table 4. Overview of therapy and overall survival.

\begin{tabular}{|c|c|c|}
\hline Pt. & Treatment lines and achieved results & $\begin{array}{c}\text { OS } \\
\text { (months) }\end{array}$ \\
\hline 1 & $1^{\text {st }}$ line: $\mathrm{CHOP}(\mathrm{SD}) \rightarrow 2^{\text {nd }}$ line: Alemtuzumab $(\mathrm{SD}) \rightarrow 1^{\text {st }}$ alloHCT $\left(1^{\text {st }} \mathrm{CR}\right) \rightarrow 1^{\text {st }}$ relaps: AraC + Mito $(\mathrm{PD}) \rightarrow$ death & 11.8 \\
\hline 2 & $1^{\text {st }}$ line: $7+3$ (daunorubicine) $\left(1^{\text {st }} \mathrm{CR}\right) \rightarrow 1^{\text {st }}$ alloHCT $\left(1^{\text {st }} \mathrm{CR}\right) \rightarrow$ end of FU $\left(1^{\text {st }} \mathrm{CR}\right)$ & 18.3 \\
\hline 3 & $\begin{array}{l}1^{\text {st }} \text { line: AML BFM } 2004\left(1^{\text {st }} \mathrm{CR}\right) \rightarrow 1^{\text {st }} \text { relaps: AML BFM 2004, RT CNS }\left(2^{\text {nd }} C R\right) \rightarrow 1^{\text {st }} \text { alloHCT }\left(2^{\text {nd }} C R\right) \rightarrow 2^{\text {nd }} \text { relaps: clofarabine }\left(3^{\text {rd }} C R\right) \\
\rightarrow 2^{\text {nd }} \text { alloHCT }\left(3^{\text {rd }} C R\right) \rightarrow 3^{\text {rd }} \text { relaps: palliative care } \rightarrow \text { death }\end{array}$ & 36.7 \\
\hline 4 & $1^{\text {st }}$ line: AIEOP BFM ALL $2009\left(1^{\text {st }} \mathrm{CR}\right) \rightarrow$ end of FU $\left(1^{\text {st }} C R\right)$ & 44.2 \\
\hline 5 & $1^{\text {st }}$ line: ALCL 99/AIEOP BFM ALL $2009(\mathrm{PD}) \rightarrow 2^{\text {nd }}$ line: AML BFM $2012(\mathrm{SD}) \rightarrow 1^{\text {st }}$ alloHCT $\left(1^{\text {st }} \mathrm{CR}\right) \rightarrow 1^{\text {st }}$ relaps: palliative care $\rightarrow$ death & 9.2 \\
\hline 6 & $1^{\text {st }}$ line: $\mathrm{CHOP}(\mathrm{PD}) \rightarrow$ death & 5.5 \\
\hline 7 & $1^{\text {st }}$ line: hyperCVAD $\left(1^{\text {st }} \mathrm{CR}\right) \rightarrow 1^{\text {st }}$ relaps: $1^{\text {st }}$ alloHCT $\left(2^{\text {nd }} \mathrm{CR}\right) \rightarrow$ death $(\mathrm{TRM})$ & 13.1 \\
\hline 8 & $1^{\text {st }}$ line: HAM $\left(1^{\text {st }} \mathrm{iCR}\right) \rightarrow 2^{\text {nd }}$ line: $1^{\text {st }}$ alloHCT $\left(1^{\text {st }} \mathrm{CR}\right) \rightarrow$ death $(\mathrm{TRM})$ & 16.4 \\
\hline 9 & $1^{\text {st }}$ line: $\mathrm{HAM}(\mathrm{SD}) \rightarrow 2^{\text {nd }}$ line: EIHA $\left(1^{\text {st }} \mathrm{CR}\right) \rightarrow 1^{\text {st }}$ alloHCT $\left(1^{\text {st }} \mathrm{CR}\right) \rightarrow$ end of FU $\left(1^{\text {st }} \mathrm{CR}\right)$ & 42.7 \\
\hline 10 & $1^{\text {st }}$ line: hyperCVAD $\left(1^{\text {st }} \mathrm{CR}\right) \rightarrow 1^{\text {st }}$ relaps $\rightarrow$ death & 3.3 \\
\hline 11 & $1^{\text {st }}$ line: hyperCVAD $\left(1^{\text {st }} \mathrm{CR}\right) \rightarrow 1^{\text {st }}$ relaps: $1^{\text {st }}$ alloHCT $\left(2^{\text {nd }} \mathrm{CR}\right) \rightarrow 2^{\text {nd }}$ relaps: palliative care $\rightarrow$ death & 5.6 \\
\hline 12 & $1^{\text {st }}$ line: $\mathrm{CHOEP}(\mathrm{SD}) \rightarrow 2^{\text {nd }}$ line: $\mathrm{RT}(\mathrm{PR}) \rightarrow$ end of $\mathrm{FU}(\mathrm{PR})$ & 8.1 \\
\hline 13 & $1^{\text {st }}$ line: GMALL $\left(1^{\text {st }} \mathrm{CR}\right) \rightarrow 1^{\text {st }}$ alloHCT $\left(1^{\text {st }} \mathrm{CR}\right) \rightarrow$ end of FU $\left(1^{\text {st }} \mathrm{CR}\right)$ & 35.1 \\
\hline 14 & $1^{\text {st }}$ line: $\mathrm{CHOP}\left(1^{\text {st }} \mathrm{CR}\right) \rightarrow 1^{\text {st }}$ relaps: MINE, ESHAP $\left(2^{\text {nd }} \mathrm{CR}\right) \rightarrow 2^{\text {nd }}$ relaps: RT, MTX $\rightarrow$ death & 22.0 \\
\hline
\end{tabular}

Pt. - Patient, OS - overall survival, treatment result is listed in the brackets: CR - complete remission, iCR - complete remission with incomplete hematopoietic recovery, PR - partial remission, SD - stable disease, PD - progressive disease, RT - radiotherapy, alloHCT- allogeneic hematopoietic cell transplantation, TRM - treatment-related mortality

Chemotherapy regimen abbreviations: $\mathrm{CHOP}$ - cyclophosphamide, hydroxydaunorubicine, vincristine, prednisone; AraC - cytarabine; Mito - mitoxantrone; 7+3 - cytarabine, daunorubicin; MTX - methotrexate; AML BFM 2004/ AML BFM 2012 - Berlin-Frankfurt-Münster group protocol for children and adolescent acute myeloid leukemia, AIEOP BFM ALL 2009 - Berlin-Frankfurt-Münster group protocol for children and adolescent acute lymphoblastic leukemia, ALCL 99 - protocol for childhood anaplastic large cell lymphoma, EIHA - etoposide, idarubicine, cytarabine; HAM - cytarabine, mitoxantrone; HyperCVAD - cyclophosphamide, vincristine, doxorubicine, dexamethasone; CHOEP - cyclophosphamide, doxorubicine, etoposide, vincristine, prednisone; ESHAP - etoposide, methyprednisolone, cytarabine, cisplatin; GMALL - The German Multicentre Study Group for Adult ALL protocol; MINE - ifosfamide, mesna, mitoxantrone and etoposide; For more details please see original chemotherapy treatment schedules. 


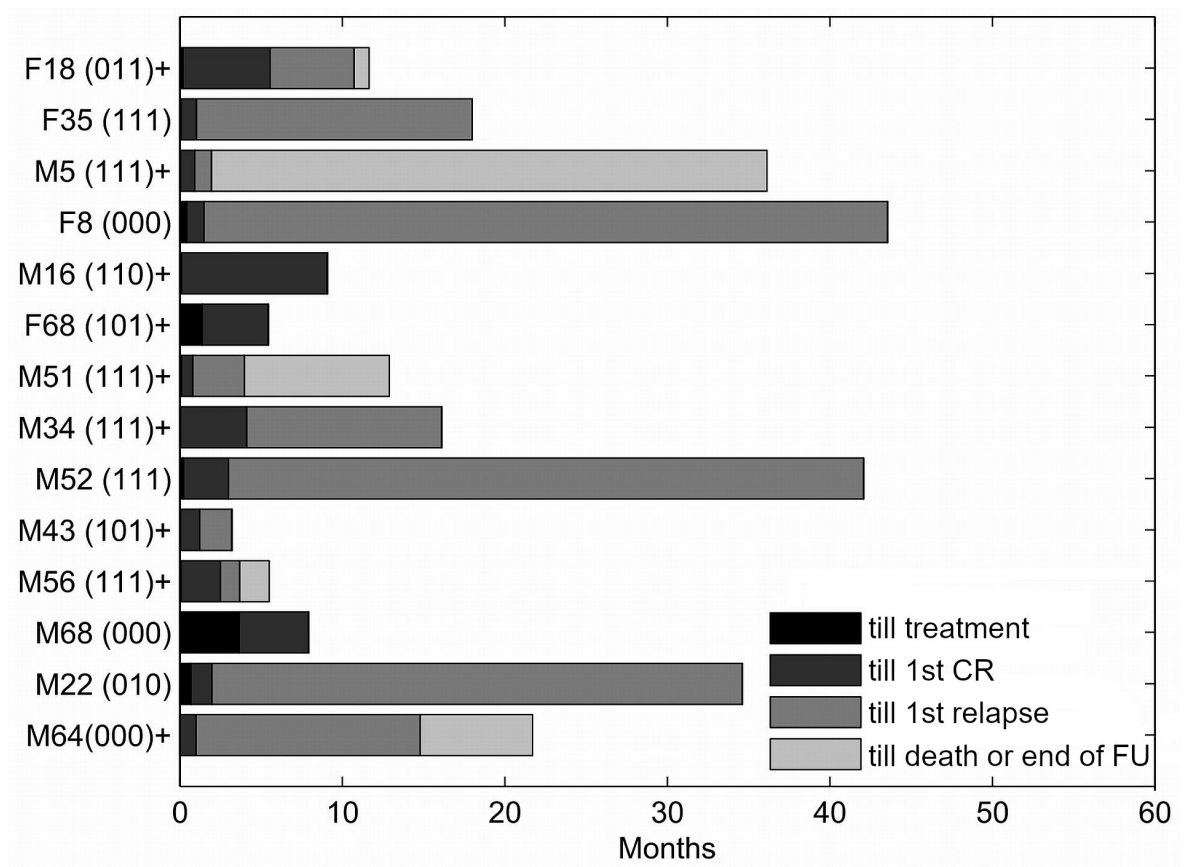

Figure 1. Overview of the patient cohort. Each row represents a single patient. Rows are ordered according to the length of follow-up. Grayscale represents the various possible states of the patients (see the legend). The text string on the left codes for all the patient characteristics in the following way: [sex][age][generalized disease][allogeneic bone marrow transplantation][bone marrow involvement][death] Legend: $M$ - male, $F$ - female, patient age (years), 1 = yes / 0 = no, + patient died in the study period, FU - follow up; For example, the most upper patient is coded as F8(000) which means a female patient aged 8 years at diagnosis, generalized disease $=$ no, allogeneic bone marrow transplantation $=$ no, bone marrow involvement $=$ no, the patient was alive at the end of follow-up.

$6,13]$. The condition must be considered in case of atypical skin manifestations inadequately responding to the treatment; therefore, other signs must be sought (particularly changes in the blood count) and histological examination ordered in time [26]. In the relatively small patient sample in the present study, atypical sites were involved, namely the jejunum, nasopharynx, lungs, and gingivae at relapse. Our results are consistent with previously published cohorts describing the involvement of extramedullary sites as pleural fluid, paranasal cavities, soft tissues and CNS particularly in relapse, suggesting the possibility of involvement of any tissue with BPDCN $[4,9,14]$.

A sufficiently wide range of immunophenotyping tests may contribute to the early identification of BPDCN patients and, at the same time, to distinguishing conditions with a partly identical immunophenotyping profile, that is, extranodal CD56+ NK/T-cell lymphoma, cutaneous T-cell lymphoma or acute leukemia difficult to classify [1]. In their analysis of 91 patients, Julia et al. showed a highly specific positivity of at least four of the markers CD4, CD56, CD123, TCL1, and CD303 for diagnosing BPDCN [27]. All patients in our study tested for CD4, CD56, CD43, and CD123 expression were positive, which confirms usefulness in the diagnosis of BPDCN. Initial assays to detect the presence of CD123 (interleukin-3-receptor-alpha) may, in addition to the diagnosis, identify patients potentially benefiting from treatment with the conjugated antibody SL-401 [19].

In the present study, four patients (29\%) were found to have chromosome 8 aberrations. In previously published samples, the $8 \mathrm{q} 24 / M Y C$ rearrangement associated with translocation $(6 ; 8)(\mathrm{p} 21 ; \mathrm{q} 24)$ has been repeatedly reported, potentially representing the first genetically defined BPDCN subgroup [28, 29]. Other signaling pathways involved in the pathogenesis of BPDCN remain a subject of intense research. Important findings are both high $B C L-2$ expression in BPDCN and the fact that in in vitro models, response to venetoclax was not affected by the mutational status of other genes [30]. Understanding the genetic mutations is essential for research on the disease and development of targeted drugs, as well as for their use as markers in the monitoring of minimal residual disease.

The reported patient cohorts showed higher CR rates achieved with intensive chemotherapy for induction ALL treatment and generally better survival in patients receiving allogeneic HCT $[9,13,26]$. Similar results, with patients benefiting from an intensive therapeutic approach, were noted in the present study. Nine out of 14 (64\%) patients achieved CR (including one iCR) after the first cycle of treatment. The use of protocols for ALL with a broader spectrum of cytostatic drugs in the first chemotherapy cycle appears 
to be more reasonable than protocols for AML therapy. However, given fact that the disease originates in the myeloid precursor, administration of medium/high-dose cytarabine analogous to AML treatment is justified [1]. Another effective cytostatic drug seems to be idarubicin, which proved even more effective than SL-401 as monotherapy in in vitro models [31]. According to Poret et al., BPDCN therapy should be based on a protocol combining methotrexate, idarubicin, L-asparaginase and dexamethasone, that is, drugs that proved effective in retrospective analyses [16].

Performing allogeneic HCT in the first complete remission has a significant impact on prolonging overall survival as compared to patients transplanted outside remission [15, 32]. In the present study, however, all patients receiving allogeneic HCT during non-CR state of disease $(2 \times \mathrm{SD}, 2 \times$ relapse and one patient with iCR) achieved CR after the transplantation. Allogeneic HCT represents potentially effective salvage therapy in patients with relapsing/refractory disease, good general condition and unavailable therapy in clinical studies which, however, should be preferred in these patients. Autologous HCT may be an alternative to consolidation therapy in patients unable to undergo allogeneic HCT or if a suitable donor is not available [33].

The CNS involvement was noted only in one patient at diagnosis, interestingly blasts were proved in cerebrospinal fluid during the first and third, but not the second relapse of BPDCN in this patient. Persistence of the blast cells in cerebrospinal fluid, particularly in patients with refractory or relapsing disease, cannot rule out inadequate transport of systemic chemotherapy across the blood-brain barrier. Therefore, initial cerebrospinal fluid examination and intrathecal prophylaxis should be included in the initial treatment protocol $[1,9,14]$. Low incidence of CNS involvement at first relapse in our cohort may be due to high proportion of patients (12/14) treated in the first-line according to ALL/lymphoma-like protocols and $\mathrm{HD}$-AraC-like protocols containing high-dose cytarabine and methotrexate with good penetration across blood-brain barrier as well as intrathecal application of the chemotherapy as prophylaxis of CNS involvement at diagnosis in 9/14 patients. Martín-Martín et al. reported significantly more frequent CNS involvement in patients with bone marrow infiltration ( $\geq 20 \%$ of blasts) [34]. Although bone marrow infiltration was seen in 9/14 patients CNS involvement was infrequent in our cohort.

Non-intensive therapeutic approaches, such as excision of an isolated lesion, focal radiotherapy, corticosteroids, and low-dose chemotherapy may represent palliative treatment modalities in patients unable to undergo intensive therapy, with a median survival of 6-9 months $[4,18]$.

The published data suggest a better prognosis in childhood [13]. The core treatment for BPDCN in children should be ALL-like chemotherapy with prophylaxis of CNS involvement and HCT is indicated in patients with relapse or only partial response to the first-line therapy [35]. The only long- term CR without HCT was observed in an 8-year-old patient after protocol for children ALL. All adult patients with longterm CR underwent HCT, which advocates the role of HCT in adults.

As an aggressive hematologic malignancy, BPDCN is initially relatively sensitive to chemotherapy, with $60-90 \%$ of patients achieving a complete remission of their disease $[4,6]$. However, there is still a high percentage of relapses with only short median survival and considerably limited therapeutic options due to rapid systemic dissemination. Despite advances in the diagnosis and treatment of BPDCN, the prognosis of most patients remains unfavorable, with a median survival of several months or, rarely, several years in those receiving allogeneic transplantation. The therapy is limited by the development of the disease in elderly patients often unable to undergo intensive salvage therapy or allogeneic HCT. Therefore, a prerequisite for further improvement of prognosis will be the development of novel effective drugs with acceptable toxicity also suitable for elderly patients with comorbidities. Given the low incidence of the disease, international registries and cooperative groups will have to be established to allow further advances in the diagnosis, classification, and treatment of BPDCN. To improve treatment outcomes, a more detailed understanding of the disease biology will be essential, together with the study of the signaling pathways and development of novel targeted drugs. Because of the rare incidence of the disease and thus a lack of prospective studies, the retrospective analysis continues to be crucial for assessing the biology and therapy of BPDCN.

Acknowledgments: This work was supported by the IGA_ LF_2019_001.

\section{References}

[1] PAGANO L, VALENTINI CG, GRAMMATICO S, PULSONI A. Blastic plasmacytoid dendritic cell neoplasm: diagnostic criteria and therapeutical approaches. Br J Haematol 2016; 174: 188-202. https://doi.org/10.1111/bjh.14146

[2] BUENO C, ALMEIDA J, LUCIO P, MARCO J, GARCIA R et al. Incidence and characteristics of CD4(+)/HLA DRhi dendritic cell malignancies. Haematologica 2004; 89: 58-69.

[3] JULIA F, PETRELLA T, BEYLOT-BARRY M, BAGOT M, LIPSKER D et al. Blastic plasmacytoid dendritic cell neoplasm: clinical features in 90 patients. Br J Dermatol 2013; 169: 579-586. https://doi.org/10.1111/bjd.12412

[4] REIMER P, RUDIGER T, KRAEMER D, KUNZMANN V, WEISSINGER $\mathrm{F}$ et al. What is CD4+CD56+ malignancy and how should it be treated? Bone Marrow Transplant 2003; 32: 637-646. https://doi.org/10.1038/sj.bmt.1704215

[5] FEUILLARD J, JACOB MC, VALENSI F, MAYNADIE $\mathrm{M}$, GRESSIN $\mathrm{R}$ et al. Clinical and biologic features of CD4+CD56+ malignancies. Blood 2002; 99: 1556-1563. https://doi.org/10.1182/blood.v99.5.1556 
[6] FACCHETTI F, PETRELLA T, PILERI SA. Blastic plasmacytoid dendritic cell neoplasm, pp 174-177. In: SWERDLOW SH, CAMPO E, HARRIS NL, JAFFE ES, PILERI SA et al (Eds.). WHO classification of tumours of haematopoietic and lymphoid tissues, revised 4th Edition. IARC, Lyon 2017, p 586. ISBN 9789283244943

[7] FACCHETTI F, CIGOGNETTI M, FISOGNI S, ROSSI G, LONARDI $S$ et al. Neoplasms derived from plasmacytoid dendritic cells. Mod Pathol 2016; 29: 98-111. https://doi. org/10.1038/modpathol.2015.145

[8] LEROUX D, MUGNERET F, CALLANAN M, RADFORDWEISS I, DASTUGUE $\mathrm{N}$ et al. CD4+, CD56+ DC2 acute leukemia is characterized by recurrent clonal chromosomal changes affecting 6 major targets: a study of 21 cases by the Groupe Francais de Cytogénétique Hématologique. Blood 2002; 99: 4154-4159. https://doi.org/10.1182/blood. v99.11.4154

[9] PAGANO L, VALENTINI CG, PULSONI A, FISSOGNI S, CARLUCCIO P et al. Blastic plasmacytoid dendritic cell neoplasm with leukemic presentation: an Italian multicenter study. Haematologica 2013; 98: 239-246. https://doi. org/10.3324/haematol.2012.072645

[10] STENZINGER A, ENDRIS V, PFARR N, ANDRULIS M, JOHRENS $\mathrm{K}$ et al. Targeted ultra-deep sequencing reveals recurrent and mutually exclusive mutations of cancer genes in blastic plasmacytoid dendritic cell neoplasm. Oncotarget 2014; 5: 6404-6413. https://doi.org/10.18632/oncotarget. 2223

[11] JARDIN F, RUMINY P, PARMENTIER F, TROUSSARD $\mathrm{X}$, VAIDA I et al. TET2 and TP53 mutations are frequently observed in blastic plasmacytoid dendritic cell neoplasm. Br J Haematol 2011; 153: 413-416. https://doi.org/10.1111/ j.1365-2141.2010.08556.x

[12] DIJKMAN R, VAN DOORN R, SZUHAI K, WILLEMZE $\mathrm{R}$, VERMEER $\mathrm{MH}$ et al. Gene-expression profiling and array-based CGH classify CD4+CD56+ hematodermic neoplasm and cutaneous myelomonocytic leukemia as distinct disease entities. Blood 2007; 109: 1720-1727. https://doi. org/10.1182/blood-2006-04-018143

[13] KIM MJ, NASR A, KABIR B, DE NANASSI J, TANG K et al. Pediatric Blastic Plasmacytoid Dendritic Cell Neoplasm: A Systematic Literature Review. J Pediatr Hematol Oncol 2017; 39: 528-537. https://doi.org/10.1097/ MPH.0000000000000964

[14] TSAGARAKIS NJ, KENTROU NA, PAPADIMITRIOU KA, PAGONI M, KOKKINI G et al. Acute lymphoplasmacytoid dendritic cell (DC2) leukemia: results from the Hellenic Dendritic Cell Leukemia Study Group. Leuk Res 2010; 34: 438-446. https://doi.org/10.1016/j.leukres.2009.09.006

[15] KHARFAN-DABAJA MA, RELJIC T, MURTHY HS, AYALA E, KUMAR A. Allogeneic Hematopoietic Cell Transplantation Is an Effective Treatment for Blastic Plasmacytoid Dendritic Cell Neoplasm in First Complete Remission: Systematic Review and Meta-analysis. Clin Lymphoma Myeloma Leuk 2018; 18: 703-709. https://doi.org/10.1016/j. clml.2018.07.295
[16] PORET E, VIDAL C, DESBROSSES Y, DELETTRE FA, PAGADOY M et al. How to Treat Blastic Plasmacytoid Dendritic Cell Neoplasm (BPDCN) Patients: Results on 86 Patients of the French BPDCN Network. Blood 2015; 126: 456. https://doi.org/10.1182/blood.V126.23.456.456

[17] ALSIDAWI S, MARCONDES WESTIN GF, AL-KALI A, GO RS. Blastic Plasmacytoid Dendritic Cell Neoplasm. A Population-Based Analysis from the SEER and NCDB Databases. Blood 2016; 128: 4789. https://doi.org/10.1182/blood. V128.22.4789.4789

[18] DALLE S, BEYLOT-BARRY M, BAGOT M, LIPSKER D, MACHET L et al. Blastic plasmacytoid dendritic cell neoplasm: is transplantation the treatment of choice? $\mathrm{Br} \mathrm{J}$ Dermatol 2010; 162: 74-79. https://doi.org/10.1111/j.13652133.2009.09373.x

[19] FRANKEL AE, WOO JH, AHN C, PEMMARAJU N, MEDEIROS BC et al. Activity of SL-401, a targeted therapy directed to interleukin-3 receptor, in blastic plasmacytoid dendritic cell neoplasm patients. Blood 2014; 124: 385-392. https://doi.org/10.1182/blood-2014-04-566737

[20] AGHA ME, MONAGHAN SA, SWERDLOW SH. Venetoclax in a Patient with a Blastic Plasmacytoid Dendritic-Cell Neoplasm. N Engl J Med 2018; 379: 1479-1481. https://doi. org/10.1056/NEJMc1808354

[21] PHILIPPE L, CEROI A, BOLE-RICHARD E, JENVRIN A, BIICHLE $S$ et al. Bortezomib as a new therapeutic approach for blastic plasmacytoid dendritic cell neoplasm. Haematologica 2017; 102: 1861-1868. https://doi.org/10.3324/haematol.2017.169326

[22] ARBER DA, ORAZI A, HASSERJIAN R, THIELE J, BOROWITZ MJ et al. The 2016 revision to the World Health Organization classification of myeloid neoplasms and acute leukemia. Blood 2016; 127: 2391-2405. https://doi. org/10.1182/blood-2016-03-643544

[23] SORROR ML. How I assess comorbidities before hematopoietic cell transplantation. Blood 2013; 121: 2854-2863. https://doi.org/10.1182/blood-2012-09-455063

[24] DOHNER H, ESTEY E, GRIMWADE D, AMADORI S, APPELBAUM FR et al. Diagnosis and management of AML in adults: 2017 ELN recommendations from an international expert panel. Blood 2017; 129: 424-447. https://doi. org/10.1182/blood-2016-08-733196

[25] CHESON BD, PFISTNER B, JUWEID ME, GASCOYNE $\mathrm{RD}$, SPECHT L et al. Revised response criteria for malignant lymphoma. J Clin Oncol 2007; 25: 579-586. https://doi. org/10.1200/JCO.2006.09.2403

[26] KHARFAN-DABAJA MA, LAZARUS HM, NISHIHORI T, MAHFOUZ RA, HAMADANI M. Diagnostic and therapeutic advances in blastic plasmacytoid dendritic cell neoplasm: a focus on hematopoietic cell transplantation. Biol Blood Marrow Transplant 2013; 19: 1006-1012. https://doi. org/10.1016/j.bbmt.2013.01.027

[27] JULIA F, DALLE S, DURU G, BALME B, VERGIER B et al. Blastic plasmacytoid dendritic cell neoplasms: clinicoimmunohistochemical correlations in a series of 91 patients. Am J Surg Pathol 2014; 38: 673-680. https://doi.org/10.1097/ PAS.0000000000000156 
[28] SUMARRIVA LEZAMA L, CHISHOLM KM, CARNEAL E, NAGY A, CASCIO MJ et al. An analysis of blastic plasmacytoid dendritic cell neoplasm with translocations involving the MYC locus identifies $\mathrm{t}(6 ; 8)(\mathrm{p} 21 ; \mathrm{q} 24)$ as a recurrent cytogenetic abnormality. Histopathology 2018; 73: 767-776. https://doi.org/10.1111/his.13668

[29] BODDU PC, WANG SA, PEMMARAJU N, TANG Z, HU $S$ et al. 8q24/MYC rearrangement is a recurrent cytogenetic abnormality in blastic plasmacytoid dendritic cell neoplasms. Leuk Res 2018; 66: 73-78. https://doi.org/10.1016/j. leukres.2018.01.013

[30] MONTERO J, STEPHANSKY J, CAI T, GRIFFIN GK, CABAL-HIERRO L et al. Blastic plasmacytoid dendritic cell neoplasm is dependent on BCL2 and sensitive to venetoclax. Cancer Discov 2017; 7: 156-164. https://doi. org/10.1158/2159-8290.CD-16-0999

[31] ANGELOT-DELETTRE F, ROGGY A, FRANKEL AE, LAMARTHEE B, SEILLES E et al. In vivo and in vitro sensitivity of blastic plasmacytoid dendritic cell neoplasm to SL-401, an interleukin-3 receptor targeted biologic agent. Haematologica 2015; 100: 223-230. https://doi.org/10.3324/haematol.2014.111740
[32] KHARFAN-DABAJA MA, AL MALKI MM, DEOTARE U, RAJ RV, EL-JURDI N et al. Hematopoietic cell transplantation for blastic plasmacytoid dendritic cell neoplasm: a North American multicentre collaborative study. Br J Haematol 2017; 179: 781-789. https://doi.org/10.1111/bjh.14954

[33] AOKI T, SUZUKI R, KUWATSUKA Y, KAKO S, FUJIMOTO $\mathrm{K}$ et al. Long-term survival following autologous and allogeneic stem cell transplantation for blastic plasmacytoid dendritic cell neoplasm. Blood 2015; 125: 3559-3562. https://doi.org/10.1182/blood-2015-01-621268

[34] MARTIN-MARTIN L, ALMEIDA J, POMARES H, GONZALEZ-BARCA E, BRAVO P et al. Blastic plasmacytoid dendritic cell neoplasm frequently shows occult central nervous system involvement at diagnosis and benefits from intrathecal therapy. Oncotarget 2016; 7: 10174-10181. https:// doi.org/10.18632/oncotarget.7101

[35] JEGALIAN AG, BUXBAUM NP, FACCHETTI F, RAFFELD M, PITTALUGA S et al. Blastic plasmacytoid dendritic cell neoplasm in children: diagnostic features and clinical implications. Haematologica 2010; 95: 1873-1879. https://doi. org/10.3324/haematol.2010.026179 